\title{
Greening Design of Urban Semi-underground Space
}

\author{
Chen $\mathrm{Yu}$ \\ Shanghai Urban Construction Vocational College, Shanghai, China
}

\begin{abstract}
Urban space greening is of great significance for improving urban underground space environment. At present, the design of urban underground space in China mostly involves the design of underground space. However, very rare research has been conducted on the design of semi-underground space greening to date. Through case study and survey research, this study focuses on the design of domestic semi-underground space, the preliminary semi-underground space greening design scheme, and the concrete implementation process of the semi-underground public space green wall greening design. The current study employs the green wall project in a semi-underground space environment as an example to illustrate the application of greening design in urban semi-underground space, and provide guidance for future ecological design of semiunderground public space.
\end{abstract}

\section{Introduction}

Theories and methods of urban underground public space ecology and greening design are emerging topics, and there is still a lack of systematic and comprehensive research. However, the construction of ecological cities in various countries around the world and the relevant personnel of the construction industry at home and abroad have conducted many studies and practices in the areas of ecological architecture and underground space planning and design. These theoretical and practical results are precisely the results of further research in this paper.

Underground public space is divided into three categories according to the environment in which the space is located: 1) all underground spaces with closed spaces and poor natural light conditions; 2) partly underground and partly on the ground. A semiunderground space that is closed and can receive part of the sun; the ground and the underground are transitioned through an open sunken plaza, a sunken space with sufficient sunlight.

The sunken space is quite an ideal underground space because its greening environment is similar to the ground greening. City sunken plaza is the most typical sunken space. The greening of the sunken space is minimally affected by its environment. It can be used to plant threedimensional greening on the vertical surface of its setback, as shown in Figure 1, or large tree species can be used to set a fixed planting pool, and it can also be moved with seasonal flowers Type combination greening. Because the sunken plaza is densely populated, it is not suitable for planting a large number of lawns and other poorly shaded plants, but the height difference with the ground can be used to set up waterfalls or fountains and other water features in some areas to improve the ecosystem of the sunken space, as shown in Figure 2. Public underground spaces such as subway stations, civil air defense facilities, and underground pedestrian streets are mostly all underground spaces. The greening design can consider vertical greening of walls, partial greening of stairs, and comprehensive greening of aisles. The public space in the whole basement is difficult to be exposed to sunlight and cannot be lighted naturally, which has caused great difficulties to the growth of plants. It is advisable to choose plants that are shade-tolerant, strong in life, and suitable for indoor growth, such as Chlorophytum, pachyderm, and peach leaves Corals, vines, etc., to provide artificial light when necessary. The whole underground space mainly adopts mobile container combined greening, and planting ponds can also be considered in larger spaces.

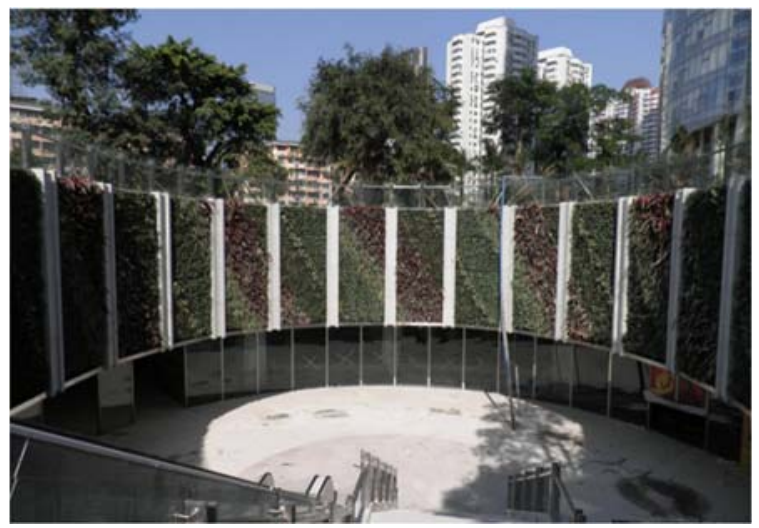

Fig 1. Sunken square vertical surface planting.

Semi-underground space mostly refers to the underground atrium space with atrium patio. Due to the existence of the atrium, the day lighting conditions in the semi-basement space are generally better. Even if there is no space with a glass ceiling, the day lighting is relatively

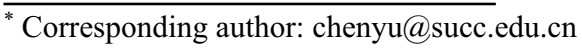


sufficient. The choice of plant species is relatively good. It is advisable to choose shade-tolerant plants and southern sunlight plants, such as ivy, chlorophytum, bamboo and some ficus plants. The plant growth height should be adapted to the size of the atrium.

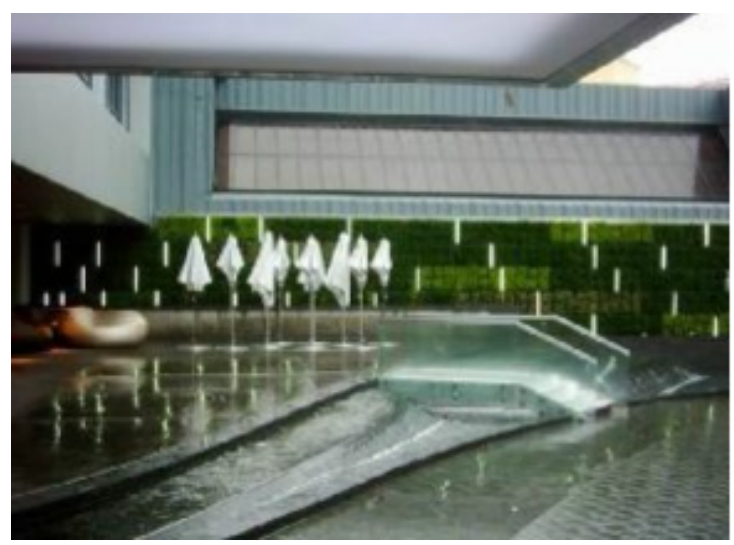

Fig 2. Sunken square waterscape ecology.

Underground space also has a wide range of options for spatial greening technology. Fixed planting ponds can be used for greening, which can be used for water body greening, vertical greening, etc., or combined greening with mobile containers. The structure of the underground atrium space is often a vertical superimposed space enclosed by multistore buildings, and its walls are also very suitable for vertical greening.

In this study, we took Zhaoxiang project of Shanghai Greenland Group as an example of a green wall project on the first floor of an underground complex to illustrate the design for a typical semi-underground space. Focus on researching the greening technology strategy of underground public space, in order to create a more intuitive and good environment close to nature for people. The research results of this thesis hope to have theoretical value and practical guiding significance in designing more comfortable human senses, more efficient use of resources, and more friendly environment, especially the ecological urban underground public space based on greening.

\section{Plant selection in underground public spaces}

Comprehensive consideration of the various ecological factors of the underground space and the protection of the underground space building facilities, in the selection of plant varieties, it has strong adaptability and tolerance to low air humidity, dim light, poor ventilation and temperature changes, and shallow roots mainly shadetolerant, greenhouse landscape plants. According to the characteristics of the underground public space environment, for the full basement, semi-basement, and sunken space environments, the selection of plants requires high ornamental value to facilitate the formation of different forms of plant landscapes; mainly evergreen foliage plants. Configure various flowering shrubs and climbing plants; the natural growth height and crown width of shade-tolerant plants, greenhouse plants and trees should be adapted to the underground space. In addition, when the lighting conditions in semi-basements and sunken underground public spaces are better, you can also consider adding light-loving and cold-tolerant plants. Commonly selected plants are shown in Table 1.

Table1. Summary table of commonly selected plants in underground public spaces.

\begin{tabular}{|c|c|c|c|}
\hline Plant name & species & Characteristics & $\begin{array}{c}\text { Environmental } \\
\text { requirements }\end{array}$ \\
\hline Boston Fern & $\begin{array}{l}\text { Perennial evergreen fern } \\
\text { herb }\end{array}$ & Likes warmth & $\begin{array}{l}\text { Humid and semi-shade } \\
\text { environment }\end{array}$ \\
\hline Fourleaf Peperelder & Perennial foliage plant & Likes warmth & $\begin{array}{l}\text { Humid and semi-shade } \\
\text { environment }\end{array}$ \\
\hline Ceriman & Perennial foliage plant & Likes warmth & $\begin{array}{l}\text { Humid environment, } \\
\text { avoid direct sunlight }\end{array}$ \\
\hline Golden pothos & $\begin{array}{c}\text { Perennial evergreen } \\
\text { vine }\end{array}$ & Likes warmth & Humid environment \\
\hline Gold Diamond & $\begin{array}{l}\text { Perennial indoor foliage } \\
\text { plant }\end{array}$ & Likes warmth & Shade tolerant \\
\hline Chlorophytum comosum & $\begin{array}{c}\text { Perennial evergreen } \\
\text { grass }\end{array}$ & Likes warmth & $\begin{array}{c}\text { Humid and semi-shade } \\
\text { environment }\end{array}$ \\
\hline Wolftailgrass & Perennial herb & Likes warmth & Semi-shade environment \\
\hline Bird's-nest fern & $\begin{array}{c}\text { Perennial shady } \\
\text { herbaceous foliage plant }\end{array}$ & High temperature & Humid environment \\
\hline Aures Kylinleaf & $\begin{array}{c}\text { Perennial evergreen } \\
\text { vine }\end{array}$ & Likes warmth & Humid environment \\
\hline Green apple & $\begin{array}{c}\text { Perennial evergreen } \\
\text { grass }\end{array}$ & High temperature & $\begin{array}{l}\text { Humidity and half shade, } \\
\text { fear of cold, avoid glare }\end{array}$ \\
\hline Adiantumleaf Corydalis & $\begin{array}{c}\text { Perennial evergreen } \\
\text { grass }\end{array}$ & Likes warmth & Avoid glare \\
\hline Arrowroot & $\begin{array}{c}\text { Perennial evergreen } \\
\text { grass }\end{array}$ & High temperature & Humidity and half shade \\
\hline Kidney fern & $\begin{array}{c}\text { Perennial evergreen } \\
\text { grass }\end{array}$ & High temperature & Humidity and half shade \\
\hline
\end{tabular}




\begin{tabular}{|c|c|c|c|}
\hline Comfrey & $\begin{array}{c}\text { Perennial evergreen } \\
\text { grass }\end{array}$ & Avoid strong light & Strong shade tolerance \\
\hline Cochinchinese Asparagus & $\begin{array}{c}\text { Perennial evergreen } \\
\text { grass }\end{array}$ & Likes warmth & Humidity and half shade \\
\hline China Ivy & $\begin{array}{c}\text { Perennial evergreen } \\
\text { herbaceous foliage } \\
\text { plants }\end{array}$ & Likes warmth & Strongshade tolerance \\
\hline Wanderingjew & $\begin{array}{c}\text { Perennial evergreen } \\
\text { herbs }\end{array}$ & Likes warmth & How wet \\
\hline Pink Palm & $\begin{array}{c}\text { Perennial flowering } \\
\text { plants }\end{array}$ & Likes warmth \\
\hline Ornamental pineapple & $\begin{array}{c}\text { Perennial evergreen } \\
\text { grass }\end{array}$ & Likes warmth & Humidity and half shade \\
\hline Dumb Cane & $\begin{array}{c}\text { Herbaceous foliage } \\
\text { flowers }\end{array}$ & Likes warmth & $\begin{array}{c}\text { Like half sunshine or } \\
\text { bright scattered light }\end{array}$ \\
\hline Peperomia caperata & $\begin{array}{c}\text { Herbaceous foliage } \\
\text { flowers }\end{array}$ & adith
\end{tabular}

\section{Design and Selection of Public Greening Wall Greening}

The specific forms of public green wall greening are as follows:

\subsection{CLIMBING or hanging type}

Climbing or hanging type is usually horizontal to the wall and the planting trough is the planting platform, that is, planting climbing or hanging vines in hanging pots (Figure 3), such as ivy (Latin scientific name: Hedera nepalensis var). sinensis (Tobl Rehd), Fufang Teng (Latin scientific name: Euonymus fortunei (Turcz.) Hand.Mazz.), Trachelospermum jasminoides (Lindl.) Lem.), creeper (Latin scientific name: Parthenocissus tricuspidata), green dill (Latin scientific name: Epipremnum aureum), Lingxiao (Latin scientific name:

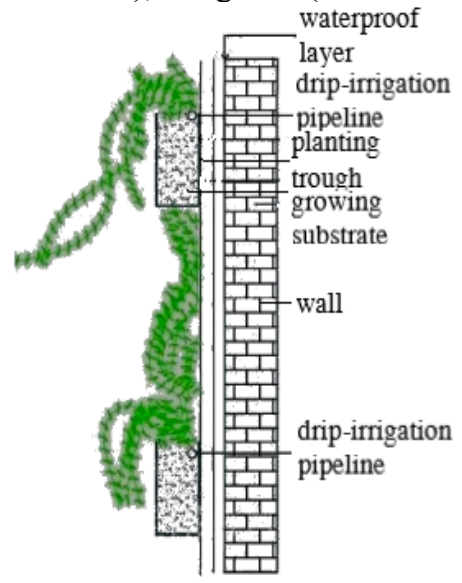

Fig 3. Climbing or hanging type.

\subsection{Modular}

Modular is the use of modular components to plant plants to achieve wall greening (Figure 5). The modular construction process is similar to that of the fancy pendulum, but the flowerpots are changed to geometric
Campsis grandiflora (Thunb.) Schum.), etc. This type of greening is simple and easy to implement, low in cost, and good in light and air permeability. However, the disadvantage is that the fallen leaves in winter reduce the ornamental, and the pattern is single, the landscaping is restricted, and the time for greening is difficult. It is difficult to evergreen in all seasons. Most have no flowers and are difficult to replace.

\subsection{Install flowerpot}

Install flowerpot is to add potted flowers in a vertical frame made of stainless steel, reinforced concrete or other materials to achieve vertical greening (Figure 4). Usually build a skeleton parallel to the wall close to the wall or 5$10 \mathrm{~cm}$ away from the wall, supplemented by drip irrigation or sprinkler irrigation system, and bear the overall weight, and then embed the pre-greened flower pots in the skeleton space.

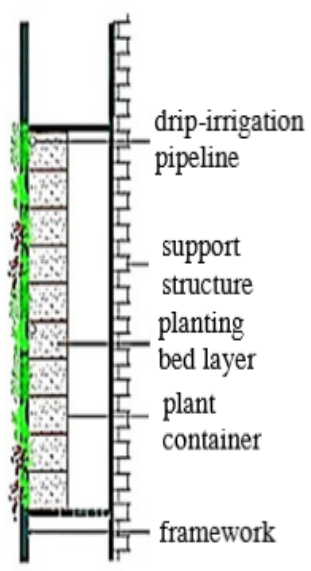

Fig 4. Install flowerpot.

modules, such as square, diamond, circular, etc. These modular combinations are more flexible and convenient. Usually, the plants and plant patterns required by customers are pre-customized in the nursery, After completing a period of cultivation and maintenance, it will be transported to the site for assembly and installation. Its advantages are automatic watering, and the system life 
is longer than the fancy style; convenient transportation and short on-site installation time; a wide variety of plants can be used, either on the ground or on the cliff; the disadvantage is that the price is relatively high, and it also needs to be added to the wall Skeleton, the thickness is greater than $20 \mathrm{~cm}$, increasing the volume may affect the appearance, the skeleton must be fixed on the wall, there is a hidden danger of water leakage at the fixed point, the overall service life of the system is affected by factors such as the rust of the skeleton, and the plants are easily caused by the failure of drip irrigation. Death due to lack of water.

\subsection{Paving type}

The paving type is to directly pave the composite plane irrigation system and the waterproof membrane of the

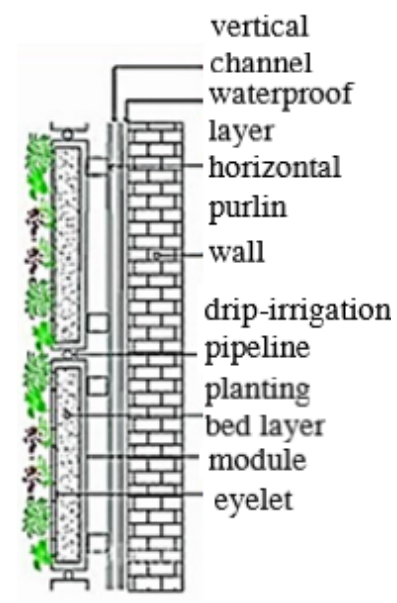

Fig 5. Modular.

\subsection{Bag-style}

Bag type (Figure 7): It is a process system developed on the basis of the pavement wall greening system, that is, a cloth bag with planted plants is nailed on a pre-made water supply pipe, waterproof layer and other systems. This process is to first install soft plant growth carriers, such as felt, coconut fiber, non-woven fabric, etc., directly on the wall that has been installed with water supply pipes and waterproofed, and then planted on these carriers with a nail gun The cloth bags of plants are pre-designed and stapled one by one. When the area is large, it is necessary to install a skeleton to strengthen it to improve its safety.

\subsection{Plate trough type}

Plate trough type (Figure 8): Install a V-shaped plate trough on the wall, fill the plate trough with a light planting substrate, and then plant various plants on the substrate. Build a skeleton parallel to the wall, supplemented by installing V-groove plates and drip irrigation or sprinkler irrigation systems, and bear the overall weight. There are several V-shaped grooves in each V-shaped plate groove, and each V-shaped groove can move freely. There are pipes at the bottom of the V- wall planting bag on the wall to form a wall planting plane system (Figure 6). This type of wall does not need extra skeleton. The plane irrigation system and the wall planting bag are compounded on a high-strength waterproof membrane through industrial production. The system is directly fixed on the wall during construction. The fixed point is a special waterproof tight. The thickness of the firmware and waterproof membrane is only $1.5 \mathrm{~mm}$. In addition to bearing the weight of the entire wall system, it also waterproofs the covered wall. Plants can be prefabricated in the nursery or planted on site. Its advantage is that plants on the ground or on the cliffs can be selected, directly attached to the wall, without additional steel frame, easy to construct, automatic watering, ultra-thin, and also has the function of waterproofing roots, which is beneficial to protect the building and extend its system Life; an integrated system is not conducive to partial adjustment in the later stage.

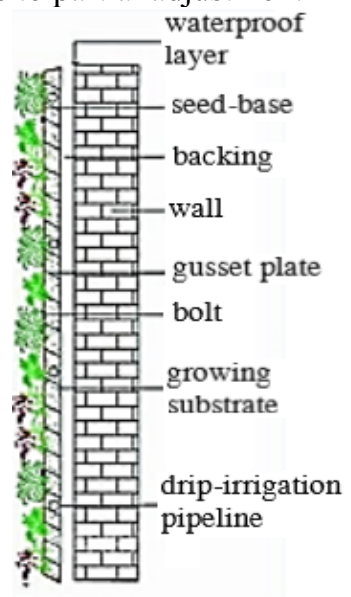

Fig 6. Paving type.

shaped groove, which can transport water and liquid nutrients for plants to absorb and drain.

\section{Case study-Shanghai Greenland Group Zhaoxiang Green Wall Project}

The Zhaoxiang project of Shanghai Greenland Group is a green wall project on the first floor of an underground complex. The fitness center on the basement level and part of the walls in the radiation area will be built as green walls. The planned wall area is $4.0 \mathrm{~m}$ in length, $5.18 \mathrm{~m}$ in height, and approximately $20.72 \mathrm{~m} 2$ of three-dimensional green walls. Bag-type plant walls are used. The walls include underground passages and part of the basement walls. The overall environment is an all-underground public space without natural light sources. The layout is shown in Figure 9, the wall in the red area is a plant wall project. The base structure of the green wall is reinforced concrete, which meets the required load of $60 \mathrm{~kg} / \mathrm{m} 2$ for the green wall. The project adopts a semi-hydroponic plane irrigation system to realize regular and quantitative irrigation. The owner must ensure that the green project adopts a semi-hydroponic plane irrigation system to achieve regular and quantitative irrigation. The owner must ensure the green wall for the irrigation method. 


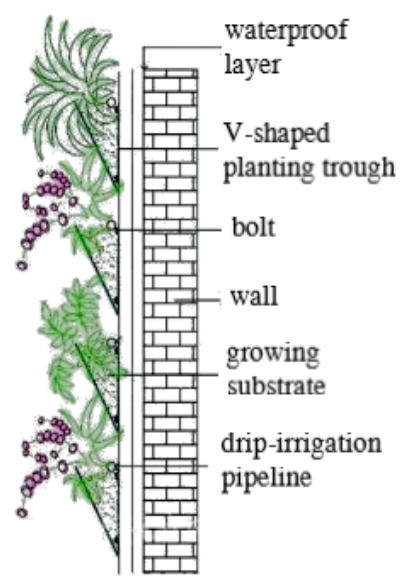

Fig 7. Bag-style.

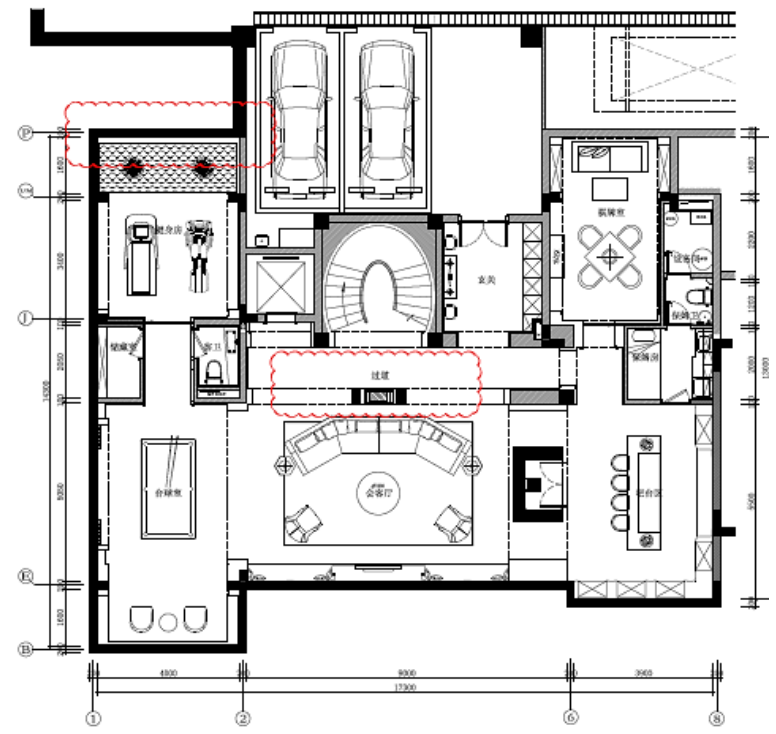

Fig 9. Layout of all underground public spaces without natural light sources.

\subsection{Bag-style greening wall design}

The plant wall is divided into eight layers: (1) Keel layer (2) Edge layer (3) Polymer waterproof layer (4) Water storage layer (5) Water retention layer (6) Advanced non-woven fabric (7) Water system layer (8) Plant layer, as shown in Figure10.

(2) The base wall does not need any treatment, and the load-bearing requirement per square meter is $40-55 \mathrm{~kg} / \mathrm{m} 2$.

(3) Keel layer: use $20 \times 40$ or $40 \times 40$ galvanized square pipes, with a spacing of $610 \times 610$ according to the project situation, and use pull parts to connect to the wall, and the intersections are treated with anti-corrosion, as shown in Figure 11.

(4) Hemming layer: 304 brushed stainless steel is used for the edging and the sink. The edging ensures the beautiful edge of the plant wall. The sink is closed and placed at the bottom of the green wall to drain the excess water left by the green wall when it is watered (Refer to Figure 12).

(5) Polymer waterproof layer: double-layer $8 \mathrm{~mm}$ thick Chevron board, staggered paving, professional glue sealing, used to prevent water flowing from the irrigation

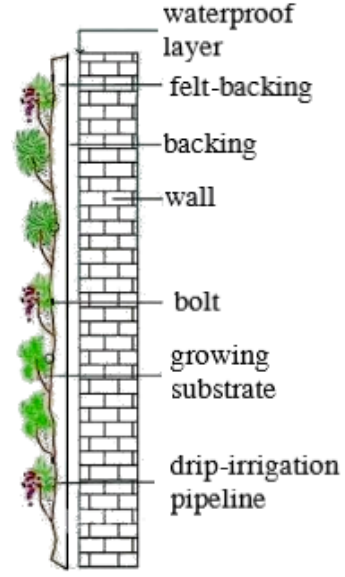

Fig 8. Plate trough type.

system from infiltrating into the wall, playing a good waterproof role, as shown in Figure 13.

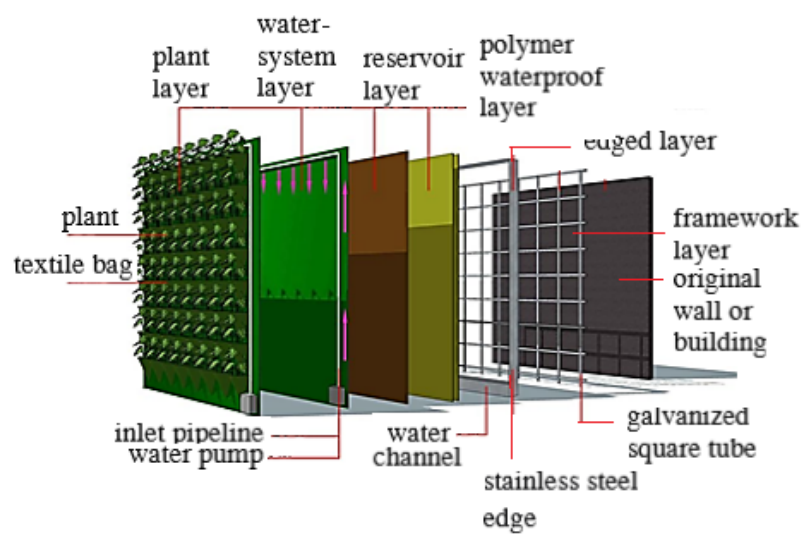

Fig 10. Layout of all underground public spaces without natural light sources.

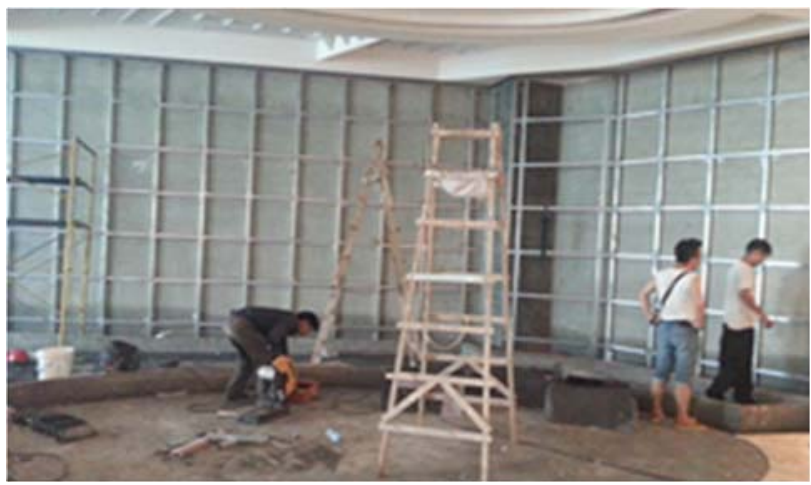

Fig 11. Plant wall keel layer layout

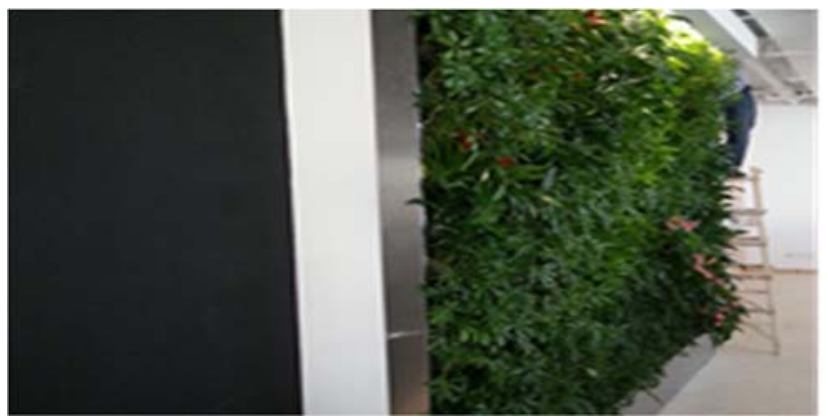

Fig 12. Plant wall edging effect 
(6) Water storage layer and water retention layer: double layer $0.5 \mathrm{~mm}$ thick cotton cloth for water storage and a layer of $0.2 \mathrm{~mm}$ thick green non-woven fabric to retain water, which can keep the water of watering plants on the wall and save water (Figure 14).

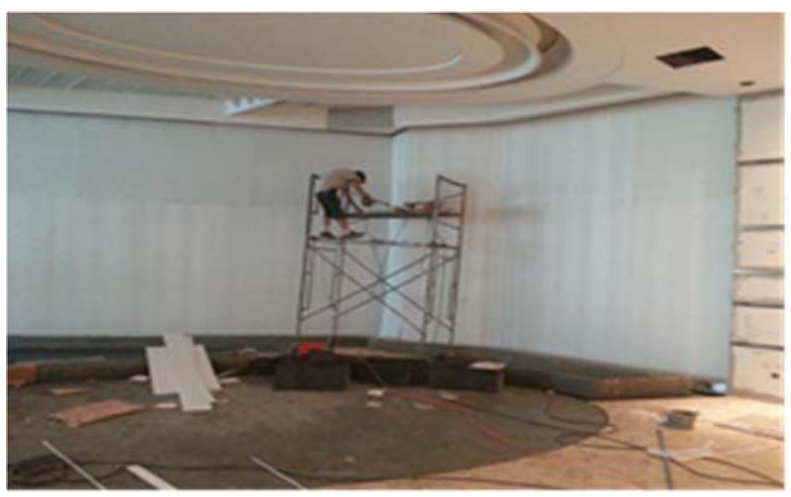

Fig 13. Waterproof layer construction

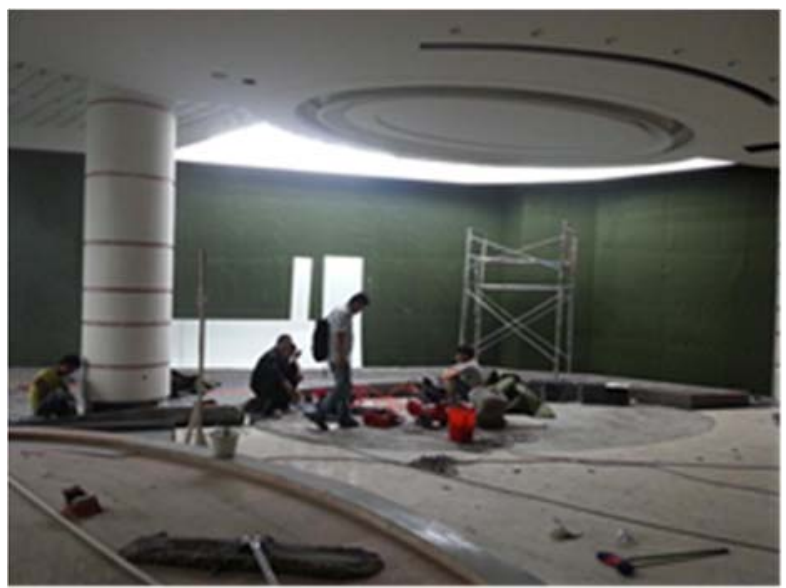

Fig 14. Construction of aquifer and water retention layer

(7) Water system layer: flat irrigation, semihydroponic irrigation system, automatic timing irrigation, water volume 5 liters $/ \mathrm{m} 2 /$ time, water pipe drilling diameter $1.5 \mathrm{~mm}$, interval $70 \mathrm{~mm}$, if the plant wall area is large or too high, Water pipes should be irrigated in layers. Choose whether to add additional valves or pressure relief valves according to the amount of water to ensure that the water needed for the normal growth of plants and the water will not flow out to the ground. After the water system is installed, debug it to ensure normal water supply in the future, As shown in Figure 15.

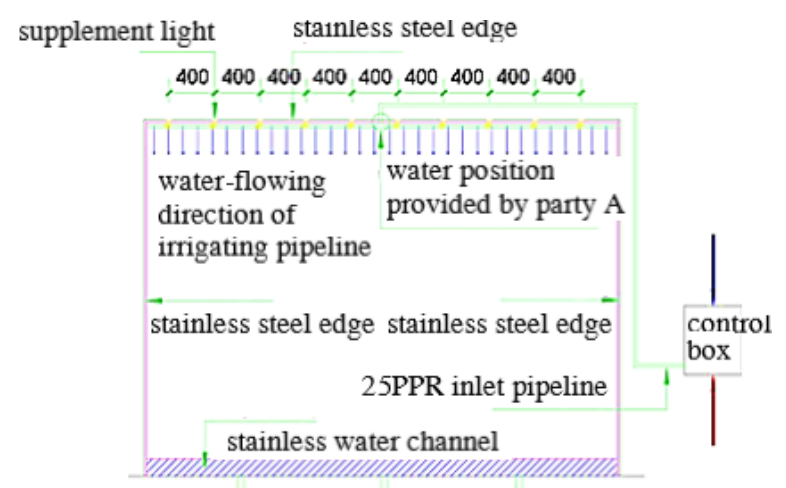

inserted drainage network

Fig 15. Schematic diagram of plant wall water system
(8) Plant layer: according to the design of the effect drawing, put the line on the above basis, draw the plant zoning map, install different plants according to different plant partitions, and the junction between different plants should be excessively natural. The plant nutrient soil is sterilized. There will be no pests and diseases. If there are insects coming in from the outside, insecticides will be carried out once every quarter. Choose to implement at night, which is colorless, odorless and harmless (as shown in Figure 16).
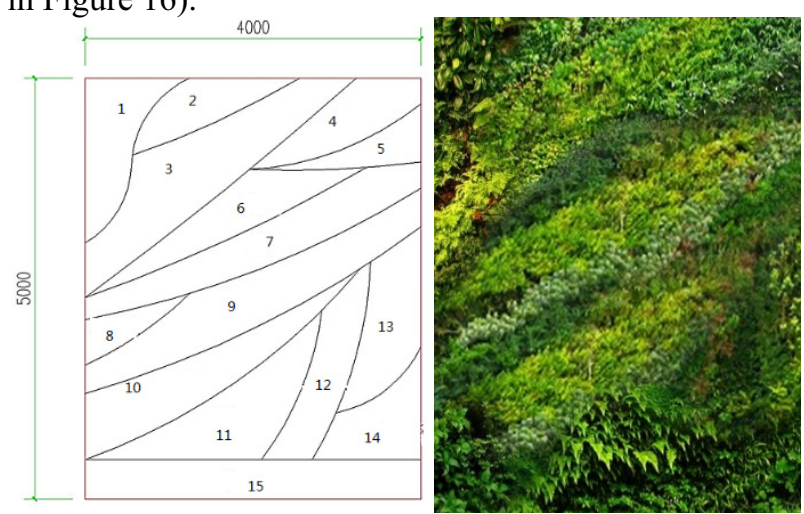

Fig 16. Plant layout and design renderings. Here, 1 represents Gold Diamond,2 represents Chlorophytum comosum,3represents Boston Fern,4 represents Green treasure,5 represents White Palm,6 represents Pink Lady, 7 represents Comfrey, 8 represents Pink Lady, 9 represents Bird's-nest fern, 10 represents Paramichelia,11 represents Green treasure,12 represents Pink Lady,13 represents Fairy, 14 represents Japan Fatsia,15 represents Aures Kylinleaf.

\subsection{Project Benefits}

The plant wall allows people to build a living environment close to nature. Due to its feature of being free from restriction of soil conditions, this plant growth-supporting system is very light. It can be installed on any wall of any material and shape without damaging the original wall structure. Under certain auxiliary conditions, such as artificial light sources, the plant wall can be laid in a semienclosed or fully enclosed space lacking or completely without natural light sources, such as the parking lot of this project. According to experiments, the plant wall has a significant effect in improving air quality. Therefore, on the surface of any building, the plant wall is an effective tool to purify the air, increase air moisture and reduce urban pollution.

The bag-type plant wall (Figure 17) improves the construction efficiency of the green wall. The operation method is simple, which can better keep the site clean and minimize the loss of plants during transportation. The bag-in-bag is all made of natural materials, environmentally friendly, clean, breathable and waterabsorbing, and is more conducive to plant growth. The bag-in-bag system is also convenient for plant replacement, making later maintenance work more efficient and reducing costs. Using the semi-hydroponic method, the installation of the water system can be greatly reduced in the construction process, and the construction cost and risk can be reduced. In addition, the cloth bag system perfectly presents the plant design pattern in the 
physical project, and the curving curve, free modeling, and hollow design can be realized, creating more creative and artistic ideas.

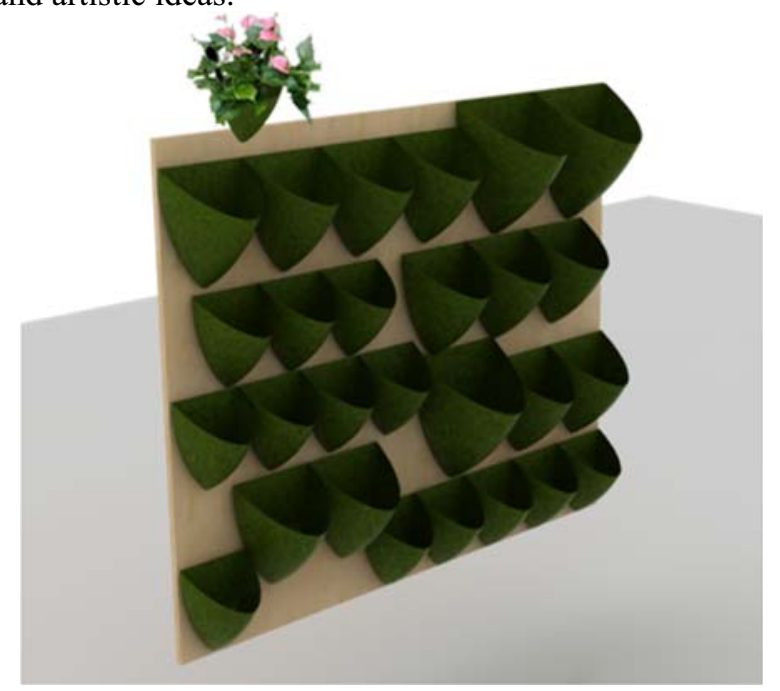

Fig 17. Bag-plant wall

\subsection{Actual effect of the project}

From the overall consideration, the combination of virtual and actual, individual locations highlights the embellishment, the lines of plants are flexible and free, different plants are ingeniously matched, and the same plants echo each other, that is elegant and not messy. The cleverly interspersed green and yellow plants make the whole wall effect richer and more beautiful. The actual effect is shown in Figure 18.

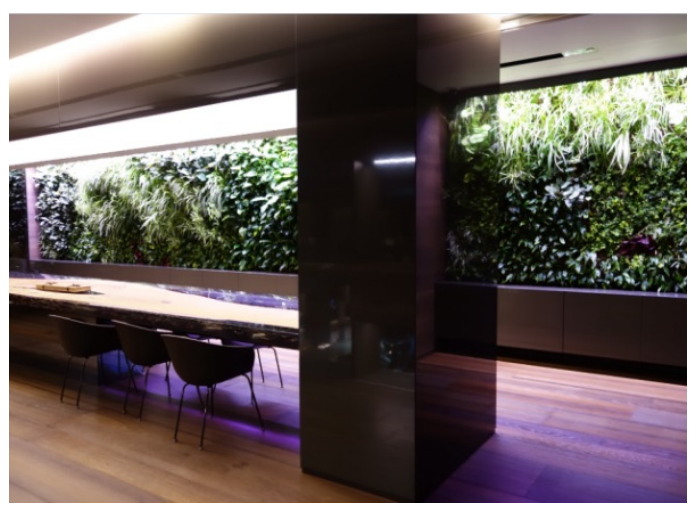

Fig 18. Actual effect of the project

\section{Conclusion}

This paper adopted the design theory of urban semiunderground public space and the concept of coordinated development of man and nature, and studied the ecological design method of urban underground public space. Taking the Zhaoxiang project of Shanghai Greenland Group as an example of a green wall project on the first floor of an underground complex, this paper discussed the design method of the green wall on the first floor of the underground complex in the underground public space and the specific layout of the green wall. Suggestions for the ecological design of underground public spaces in future cities were also provided. Provide greening technical strategies and design for underground public spaces that are close to nature, being more intuitive to better environment. The current technical content of wall greening needs to be improved urgently. In particular, the innovative value should be reflected in the application of patents and new technologies, and scientific and technological investment and government guidance should be appropriately strengthened. The disconnection between wall greening construction and house construction is the objective reason for the difficulty of wall greening promotion. In the pre-architectural design process, fully consider the combination of wall greening and the main body of construction to avoid secondary wall greening. Construction and repeated construction. Future wall greening must be unique in the greening landscape, but there are still some problems in the promotion of this technology. First, the wall greening process is mostly done by small companies or a small department of a greening company. Second, there is a lack of technical communications. Therefore, it is necessary to establish a complete wall greening system and form authoritative design specifications and acceptance standards.

\section{References}

1. Ren Lai, Di Leiyun. Building environment space greening project $[\mathrm{M}]$. Beijing: China Construction Industry Press, 2006

2. Shanghai Municipal Engineering Design and Research Institute, Tongji University, Shanghai Construction Engineering Group, etc. Comprehensive utilization and development technology of underground space in the Expo Park [R]. Shanghai: Shanghai Municipal Engineering Design and Research Institute, 2008

3. Zhou Ruwen. Research on Greening Technology of Underground Space in Expo [R]. Shanghai: Shanghai Garden Group Co., Ltd., 2009

4. Zhu Daming. Creation of landscaping environment in underground building space[J]. Underground Space, 2001, 21(1): 33-37

5. Li Tingting. Greening of underground space on the Expo Axis [J]. Garden, 2009, 12: 28.31

6. Liu Zongqun, Liming. Green residential greening environment technology [M]. Beijing: Chemical Industry Press, 2008

7. Li Tingting. Greening construction technology for underground space of Expo Axis [J]. Shanghai Construction Technology, 2008, 4:28-31

8. Zhou Ruwen, Gao Xiang, Xia Wei. Research on Greening Technology of Underground Space in Expo Park [C]. 2008 (Tenth) China Association for Science and Technology Annual Meeting, 2008

9. Chen Zhilong. Talking about the foresight and operability of urban underground space planning [J]. Chinese Journal of Underground Space and Engineering. 2006, 2(7): 1116 120 
10. Dong Deming, Bao Guozhang. Basic theoretical issues of urban ecosystem and eco-city[J], Urban Development Research. 2001, 8(added): 32-35

11. Kaliampakos, D, Benardos, A, Mavrikos, A,et. al. The Underground Atlas Project[J]. Tunnelling \& Underground Space Technology Incorporating Trenchless Technology Research: S0886779815000541.

12. Ilkka Vähäaho. An introduction to the development for urban underground space in Helsinki[J]. Tunnelling and Underground Space Technology, 2015, 55:324-328.

13. Nelson, Priscilla P. A framework for the future of urban underground engineering $[\mathrm{J}]$. Tunnelling and Underground Space Technology, 2016, 55:32-39.

14. Makana L O, Jefferson I, Hunt D V L, et al. Assessment of the future resilience of sustainable urban sub-surface environments[J]. 2016, 55: 21-31.

15. Qiao Y K, Peng F L. Lessons learnt from Urban Underground Space use in Shanghai-From Lujiazui Business District to Hongqiao Central Business District[J]. Tunnelling and Underground Space Technology incorporating Trenchless Technology Research, 2016, 55:308-319.

16. Barraud S, Azzout Y, Cres F N, et al. Selection aid of alternative techniques in urban storm drainage Proposition of an expert system[J]. Water Science \& Technology, 1999, 39(4):241-248. 